\title{
Atenção básica em saúde: um estudo de caso no município de Canguaretama/RN
}

A presente pesquisa possui como objetivo analisar a adequação dos serviços oferecidos nas Unidades Básicas de Saúde, na ótica dos pacientes, segundo o Manual de Estrutura da UBS do SUS e a Política Nacional de Atenção Básica (PNAB), em Canguaretama, município localizado no interior do estado do Rio Grande do Norte. No referencial teórico, a partir de autores como Secchi (2013), Carvalho (2013) e Souza (2003), dentre outros, foram abordados os temas relacionados à definição, o ciclo e avaliação de políticas públicas, bem como a criação do Sistema Único de Saúde (SUS). No tocante à metodologia, a pesquisa foi exploratória e quantitativa tendo ouvido 100 pacientes de quatro UBS do município, escolhidos por amostra não probabilística por conveniência, através de formulários, além de entrevistar uma enfermeira de cada unidade. Os resultados da pesquisa indicaram que, na ótica dos pacientes, há adequação dos serviços como consulta médica, enfermagem e odontologia, com os requisitos exigidos pelo SUS, mas os mesmos indicaram a necessidade de melhorias no atendimento e condições de infraestrutura das UBS.

Palavras-chave: Políticas públicas; Sistema Único de Saúde; Unidade Básica de Saúde.

\section{Basic health care: a case study in Canguaretama/RN}

\begin{abstract}
The present research has as main objective to analyze the adequacy of the services offered in the Basic Health Units (UBS), according to UBS Structure Manual and the National Policy of Primary Care (PNAB) in Canguaretama, a little city located in the Rio Grande do Norte state. In the theoretical framework, from authors such as Secchi (2013), Carvalho (2013) and Souza (2003), among others, the issues were addressed related to the definition, the cycle and evaluation of public policies and the creation of the Single System Health (SUS). Regarding methodology, the research was exploratory and quantitative, having heard 100 patients four county UBS, chosen by non-probabilistic convenience sample, through forms, and interview a nurse of each unit. The results of the research indicated that, from the point of view of the patients, there are adequate services such as medical consultation, nursing and dentistry, with the requirements required by the SUS, but they indicated the need for improvements in the care and infrastructure conditions of the UBS.
\end{abstract}

Keywords: Public policies; Health System; Basic Health Unit.

Topic: Gestão Pública

Reviewed anonymously in the process of blind peer.
Received: 12/05/2017

Approved: 14/07/2017

\section{Maria Wiedelania Ferreira Lima}

Instituto Federal do Rio Grande do Norte, Brasil

http://lattes.cnpq.br/1740385099734578

wildelanialima@gmail.com

Lenin Cavalcanti Brito Guerra

Instituto Federal do Rio Grande do Norte, Brasil

lenin.cavalcanti@ifrn.edu.br

Cláudio Márcio Campos Mendonça

Universidade Federal do Amapá, Brasil

http://lattes.cnpq.br/0548149279978063

cmarcio@gmail.com

\section{Referencing this:}

LIMA, F. W. M.; GUERRA, B. C. L.; MENDONÇA, C. M. C.. Atenção básica em saúde: um estudo de caso no município de Canguaretama/RN. Revista Brasileira de Administração Científica, v.8, n.2, p.174-189, 2017. DOI: http://doi.org/10.6008/SPC2179$\underline{684 X .2017 .002 .0023}$ 


\section{INTRODUÇÃO}

As políticas públicas são todas as ações que o governo realiza para propiciar benefícios à coletividade. Secchi (2013) define as políticas públicas como o campo do conhecimento que busca, ao mesmo tempo, colocar o governo em ação e/ou analisar essa ação (variável independente) e, quando necessário, propor mudanças no rumo ou curso dessas ações (variável dependente).

Uma das áreas mais básicas de políticas públicas é a da saúde que, no Brasil, possui no Sistema Único de Saúde (SUS) sua principal expressão. O SUS oferece atendimento universal e gratuito para todos os brasileiros, sendo um dos maiores sistemas públicos de saúde do mundo, ofertando desde o simples atendimento ambulatorial até o transplante de órgãos, garantindo acesso integral, universal e gratuito para toda a população do país. O Sistema, que trouxe nova concepção de saúde e atenção no aspecto da prevenção, proteção e recuperação da saúde, foi instituído na Constituição de 1988 e consolidou-se pelas leis 8.080 e 8.142 , ambas de 1990, para ser o sistema de saúde dos mais de 200 milhões de brasileiros.

O SUS tem como princípios básicos a universalidade, a equidade e a integralidade; no tocante às suas diretrizes, destacam-se a hierarquização, regionalização, territorialização e descentralização. Pelo desenho do sistema, o atendimento de procedimentos de menor complexidade, como consultas ambulatoriais, enfermagem e odontologia, deve ser realizado pelas Unidades Básicas de Saúde (UBS), sob responsabilidade administrativa dos municípios.

Este trabalho objetiva analisar a adequação dos serviços oferecidos nas Unidades Básicas de Saúde, segundo o Manual de Estrutura da UBS do SUS e a Política Nacional de Atenção Básica (PNAB), em Canguaretama, município localizado no interior do estado do Rio Grande do Norte, e para isso também descreve os critérios do Sistema Único de Saúde (SUS), apresentados nos documentos supracitados e avalia, pela ótica dos pacientes, os serviços prestados segundo os critérios do SUS.

\section{REVISÃO TEÓRICA}

\section{Políticas Públicas}

Não existe uma única, nem melhor definição sobre o que seja política pública. Para tanto, alguns autores se assemelham na conceituação do que seja de fato políticas públicas. Uma definição bastante simples é a que diz que a política é a resolução pacífica para os conflitos (RUA, 2012). Contudo, Rua (2012) ressalta que este é um entendimento bastante impreciso. Ainda que de maneira puramente conceitual, cabe uma distinção.

Para tanto, Secchi (2013) define as políticas públicas (public policy) como sendo as que tratam do conteúdo, técnico e simbólico, das decisões de uma política e também do processo que antecede a sua implementação, ou seja, os processos de construção e atuação dessas decisões. Sendo caracterizada como uma diretriz elaborada para o enfrentamento de um problema público.

Em outras palavras, políticas públicas implicam em responder às seguintes questões: 'quem ganha o quê?'; ‘por quê?'; e 'que diferença faz?'. Críticos dessas definições, que superestimam aspectos racionais e 
procedimentais das políticas públicas, argumentam que elas ignoram a essência da política pública, isto é, o embate em torno de ideias e interesses (HOCHMAN et al., 2014).

Para um entendimento correto do processo das políticas públicas torna-se fundamental conhecer e compreender o ciclo de políticas. Trata-se de uma abordagem para o estudo das políticas públicas que identifica fases sequenciais e interativas no processo de produção de uma política (RUA, 2012). As fases, ou seja, o ciclo das políticas públicas são: formação da agenda, formulação de alternativas, tomada de decisão, implementação e avaliação das políticas públicas.

Pode-se, então, resumir o que seja política pública como o campo do conhecimento que busca, ao mesmo tempo, 'colocar o governo em ação' e/ou analisar essa ação (variável independente) e, quando necessário, propor mudanças no rumo ou curso dessas ações e/ou entender por que e como as ações tomaram certo rumo (variável dependente). Para tanto a seguir tratar-se-á sobre a avaliação das políticas públicas a fim de relacionar ao tema abordado para melhor fixação (LOTTA, 2010).

De todas as etapas do ciclo, a que possui maior relevância para esta pesquisa é a avaliação de uma política pública, uma vez que é onde se observam os resultados obtidos com determinada política e decide-se a respeito do que será feito a respeito da política implantada. Essa fase da avaliação envolve necessariamente um julgamento, uma atribuição de valor, uma medida de satisfação ou insatisfação, tal como aprovação ou desaprovação a uma política pública (SOUZA, 2008).

O relatório da avaliação deve servir tanto para divulgação da realidade a qual vive a política pública como para que sejam criadas alternativas de melhoria através de um debate público em uma dada realidade social (THOENIG, 2000). As avaliações relacionadas às políticas públicas de saúde são o foco desse artigo com a qual avalia distintamente os serviços ofertados pelo Sistema Único de Saúde (SUS) através das Unidades Básicas de Saúde (UBS). Para tanto, no tópico a seguir será discutido a respeito do SUS e da UBS distintamente.

\section{O Sistema Único de Saúde e a política nacional de atenção básica}

O SUS foi criado pela Constituição de 1988 como forma de realizar desde o atendimento de baixa complexidade, como consultas médicas, até os de alta complexidade como transplante de órgãos. É um dos maiores sistemas de saúde do mundo e integra centros e postos de saúde, hospitais, incluindo os universitários, laboratórios, hemocentros (bancos de sangue), os serviços de Vigilância Sanitária, Vigilância Epidemiológica, Vigilância Ambiental, além de fundações e institutos de pesquisa.

Em sua política está integrado o atendimento básico realizado pelas Unidades Básicas que possuem um dos papéis fundamentais. Pois, elas são a porta de entrada para utilização desse Sistema, ou seja, elas são o primeiro contato que os pacientes devem ter com o SUS. Através do Manual de Estrutura da UBS o SUS descreve todos os critérios para que as Unidades ofereçam aos pacientes um atendimento de qualidade com uma estrutura adequada. E através da Política Nacional de Atenção Básica o SUS descreve o papel de cada profissional dentro da Unidade para que realizem os atendimentos, necessários e cabíveis, aos pacientes (CARVALHO, 2013). 
No Brasil, a atenção básica em saúde está delegada à gestão municipal. Segundo Engel et al. (2009), a atenção básica, considerada atenção primária, ou seja, o primeiro contato do paciente com o Sistema Único de Saúde (SUS), é o componente mais importante do Sistema. Seu objetivo é orientar sobre a prevenção de doenças, solucionar possíveis casos de agravos e direcionar para outros níveis de atendimento de acordo com a gravidade do problema. Carvalho et al. (2014) orienta que essa atenção primária deve ser sem restrição a grupos de idades, gênero ou problema de saúde, além de ser acessível, integrada e continuada. Nesse contexto, a atenção básica serve como um filtro que organiza o fluxo dos serviços a serem utilizados na rede de saúde orientando os pacientes para os atendimentos, dos mais simples aos mais complexos.

No Brasil, há diversos programas governamentais relacionados à atenção básica, dentre eles a Estratégia de Saúde da Família (ESF), que é proporcionado pelas Unidades Básicas de Saúde (UBS). Através dessas Unidades, a população dispões de atendimentos básicos como vacinas, verificação de pressão, visitas domiciliares, consultas médicas e odontológicas, dentre outros (TAHAN-SANTOS, 2011; SAMOTO, 2013).

A atenção básica, segundo o Ministério da Saúde (2012), envolve iniciativas, que auxiliam a promoção de uma saúde de qualidade para usuários, como os Agentes Comunitários de Saúde (ACS), que são responsáveis por visitas domiciliares aos pacientes, fazer acompanhamento de gestantes e crianças, realizar campanhas de prevenção e orientação à comunidade, dentre outros.

Com base nessas premissas, todo esse apoio à saúde pública representa uma proposta de reorganização de atenção básica como eixo de orientação de modelo assistencial, obedecendo a uma nova concepção de saúde de maneira não mais centrada somente na assistência a cura de doenças, mas, sobretudo, na promoção da qualidade de vida dos pacientes de maneira a, também, prevenir e orientar os mesmos (BRASIL, 2012).

\section{METODOLOGIA}

A presente pesquisa é classificada como exploratória e descritiva por buscar a obtenção e uma maior familiaridade com o assunto a ser tratado, além de ter obter dados de uma população e a descrição de fatos/observação dos mesmos. A presente pesquisa ainda se classifica como sendo quali-quantitativa. Quantitativa, pois possui em sua coleta de dados informações objetivas sobre o assunto abordado tal como a utilização de questionários que auxiliam na coleta de dados e para as conclusões pertinentes ao objetivo da pesquisa. Barros (2008) define o método de questionário como sendo um instrumento muito usado para o levantamento de informações. $O$ instrumento de coleta de dados, definido como questionário, foi aplicado à população usuária dos serviços oferecidos pelas Unidades Básicas de Saúde.

Em relação à característica qualitativa, foram desenvolvidas entrevistas para coleta de dados e por tratar-se de uma metodologia indutiva, onde a teoria é feita a partir de observações empíricas com ênfase na interação entre os dados e sua análise, as conclusões feitas a partir da coleta de dados podem levar a resultados prováveis.

Quanto ao momento de coleta da pesquisa, foi utilizado o corte transversal (cross-sectional study) por meio de uma amostra não probabilística por conveniência, foram aplicados 100 questionários para 
pacientes em quatro UBS do município, duas na zona rural e duas na zona urbana. A aplicação ficou sob responsabilidade de um dos pesquisadores e ocorreu durante o mês de julho de 2016.

Utilizou-se também a observação por parte da pesquisa, que segundo Barros (2008), esse tipo de método é um procedimento investigativo de suma importância na ciência, pois é por meio dele que se inicia todo o estudo dos problemas. Barros (2008) finaliza afirmando que essa técnica oferece a vantagem de possibilitar contato direto do pesquisador com os fatos.

\section{Caracterização do objeto de estudo}

O município de Canguaretama situa-se na mesorregião Leste Potiguar e na microrregião Litoral Sul do estado do Rio Grande do Norte, limitando-se com os municípios de Espírito Santo, Goianinha, Vila Flor, Baía Formosa, e Pedro Velho, o Estado da Paraíba e o Oceano Atlântico, abrangendo uma área de $245,529 \mathrm{~km}^{2}$. Situa-se à $67 \mathrm{~km}$ da capital, Natal, e é constituído pela sede e por dois distritos, o de Piquiri e o da Barra do Cunhaú (BRASIL, 2015).

Este último é cenário das duas atividades econômicas locais mais importantes: o turismo e a carcinicultura. O comércio e a agricultura também se destacam no município. O município possui uma população estimada em 2015 de 33.623 mil habitantes, sendo 18.151 mulheres e 15.472 homens, ficando em 15으 na escala de cidades populosas do estado (BRASIL 2015).

\section{RESULTADOS E DISCUSSÃO}

A presente pesquisa foi realizada no período de maio e junho de 2016, desenvolvida através da aplicação de questionários aplicados com pacientes na fila de espera para atendimento em quatro UBS localizadas na cidade de Canguaretama, mais precisamente uma em cada zona da cidade: UBS Piquiri I e UBS Piquiri II, localizadas na área Rural; UBS Sertãozinho I e UBS Lagoa de São João, localizadas na área Urbana. Além dos questionários, foram aplicadas entrevistas com responsáveis pela administração de cada Unidade, no caso, as entrevistas foram realizadas com enfermeiros.

Ao todo foram realizadas quatro entrevistas e aplicados 100 questionários, 25 em cada Unidade, dentre os quais $62 \%$ dos respondentes foi do sexo feminino e $38 \%$ do sexo feminino. Os questionários foram aplicados com pessoas entre 15 e 70 anos, usuários da Unidade, com renda de até três salários mínimos. Serão apresentadas informações detalhadas dos dados coletados durante a pesquisa. Serão mostradas tabelas e gráficos que deixa claro a situação dos serviços ofertados e da infraestrutura oferecida nas UBS de acordo com o que foi respondido pelos entrevistados e observados pela pesquisadora

\section{Perfil dos respondentes}

No tocante ao perfil dos respondentes, foram 62 mulheres e 38 homens. A tabela 1 apresenta os dados da faixa etária e renda dos respondentes. Em relação à idade, nota-se uma participação maior de pessoas entre 15 e 40 anos, totalizando 73 pessoas dos entrevistados. A frequência é menor entre pessoas de 51 a 70 por serem mais idosos e muitos deles receberem atendimento domiciliar pelos enfermeiros e 
agentes comunitários de saúde (ACS), que, por motivo de doença e/ou da idade, possuem limitações de se deslocarem até a UBS para o atendimento.

Em relação à renda, a maioria dos pacientes/usuários das UBS ouvidos possuem uma faixa etária de renda entre um e dois salários mínimos, totalizando 90 indivíduos dentre os 100 dos entrevistados, dentro do perfil socioeconômico esperado para a população de um pequeno município do interior do estado do Rio Grande do Norte.

Tabela 1: Idade dos Respondentes.

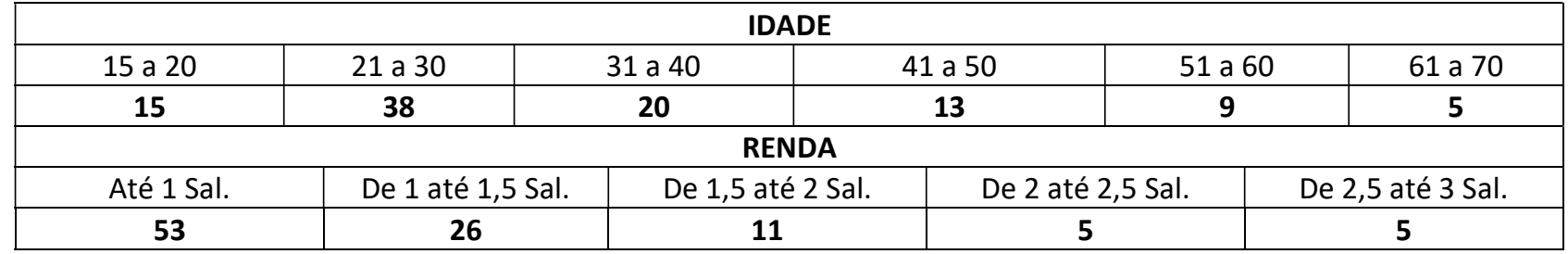

\section{Serviços oferecidos}

Nesta seção serão analisados os resultados referentes aos serviços de oferta obrigatória por parte das UBS, que consta no Manual de Estrutura da UBS e na Política Nacional de Atenção Básica (PNAB), disponibilizados pelo Ministério da Saúde. Os serviços que constam nesses documentos são os seguintes: Consultas Médicas, Odontologia, Enfermagem, Imunizações (Aplicação de Vacinas), Sala para Nebulização, Troca de Curativos, Realização de encaminhamento adequado das urgências, emergências e de casos de maior complexidade, Ambulância e Infraestrutura adequada (equipamentos necessários para o atendimento, banheiros limpos, paredes sem mofo, consultório médico com lavabo, sala de enfermagem, sala de curativos, sala de vacinas, espaço para reuniões, sala de espera, dentre outros.).

Esses são serviços básicos que devem estar presentes em todas as Unidades, obrigatoriamente. Portanto, foram questionados aos pacientes quanto a avaliação dos serviços disponíveis na Unidade. Segundo Lotta (2010), a avaliação de uma política pública pode acontecer em vários momentos da implementação. Para cada momento ela assumirá uma conotação. Diante disso, essa avaliação acontece após a implementação dessa política pública de saúde denominada oferecida pelas Unidades Básicas de Saúde (UBS). Também se obteve a participação de enfermeiros através de entrevistas para que a avaliação fosse complementada. Para tanto, a seguir vamos analisar cada um dos serviços que foram citados anteriormente.

\section{Consulta médica}

Inicialmente os respondentes foram questionados como avaliam a consulta médica realizada na UBS do seu bairro. Do total, $10 \%$ consideraram este serviço ótimo; $61 \%$ consideram bom; $23 \%$ consideraram regular; $3 \%$ consideraram ruim; $3 \%$ consideraram péssimo, conforme retrata o gráfico 1 , que traz em seu bojo o percentual sobre a consulta médica. 


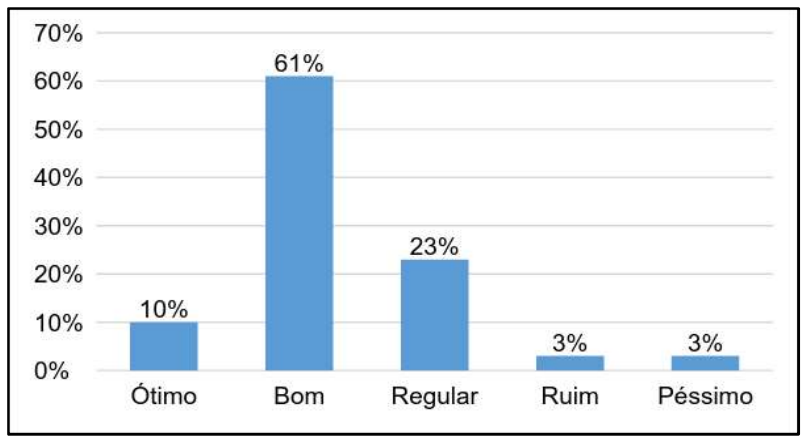

Gráfico 1: Consulta Médica.

Neste gráfico nota-se que houve um bom resultado para a avaliação das consultas médicas realizadas nas Unidades, visto que $71 \%$ dos entrevistados consideram esse serviço ótimo ou bom. Em entrevista com as enfermeiras das Unidades entrevistadas, pode-se saber sobre os atendimentos nas Unidades. Baseado na entrevista, nota-se que houve uma avaliação positiva por parte dos usuários pelo fato de haver atendimentos todos os dias, atendendo às recomendações do Manual de Estrutura da UBS do SUS e da Política Nacional de Atenção Básica (PNAB).

[...] São distribuídos, especificamente, para cada dia da semana, aleatório, de acordo com o planejamento da UBS, como sendo: saúde do homem, saúde da mulher, puericultura, pediatria, Hipertensos, Diabéticos, Pré-Natal. A UBS realiza os atendimentos de urgência e emergência acessíveis a Unidade todos os dias da semana, meio dia na semana é para visita domiciliar, algumas vezes o (a) médico (a) participa do PSE (Programa Saúde na Escola) juntos com toda a equipe da Unidade (ENTREVISTA, 2016).

No entanto, é importante apontar ponto negativo identificado: $6 \%$ dos entrevistados classificaram como ruim e péssimo para o serviço de consulta médica. O motivo de não satisfação com esse serviço, segundo esses entrevistados são diversos, dentre eles 'apenas um médico atende na Unidade por dia por isso a quantidade de fichas distribuídas são poucas e o número de pacientes aumenta'; 'o tempo de atendimento com o médico é pequeno'. De acordo com o que foi observado pela pesquisadora, isso, de fato, ocorre, principalmente por só haver um médico. O acúmulo de pessoas se dá, em grande parte, porque as fichas são distribuídas das $7 \mathrm{~h}$ às $7 \mathrm{~h} 30$, porém o médico só chega depois das $9 \mathrm{~h}$ da manhã e atende até $11 \mathrm{~h} 30$, e das $14 \mathrm{~h}$ às $16 \mathrm{~h}$ no período da tarde.

Segundo Secchi (2013), avaliar consiste em aplicar um julgamento para a política pública com a qual se pretende avaliar, tal como a determinação de critérios para que sejam coletados dados válidos e legítimos sobre a política. Garcia (2001) complementa dizendo que avaliação de políticas públicas consiste em avaliar os resultados de acordo com os objetivos propostos. Portanto, a avaliação realizada se deu a partir dos critérios determinados pelo SUS descritos nos documentos citados acima.

Pode-se acrescentar um outro tipo de avaliação definido por Lotta (2010), a avaliação in itinere, que é conhecida também como avaliação formativa ou monitoramento. Ou seja, uma forma de monitoramento desses profissionais quanto aos horários de chegada e saída da UBS. Diante do que foi exposto pode-se concluir que em relação às consultas médicas realizadas nas Unidades Básicas de Saúde estão próximas com o que é descrito nos documentos do SUS. Isso reflete positivamente na avaliação da população como foi observado no gráfico apresentado acima. Porém, é viável destacar que para atingir o índice de total 
conformidade é preciso que os gestores das UBS refaçam o planejamento para que melhor atendam os pacientes e diminuam os índices de reclamação.

\section{Odontologia}

A segunda questão a respeito dos serviços foi em relação à odontologia. Questionou-se aos respondentes sobre o atendimento realizado pelo (a) dentista na Unidade frequentada por ele (a) em seu bairro. Do total, $14 \%$ consideraram este serviço ótimo; $51 \%$ consideraram bom; $26 \%$ consideraram regular; $8 \%$ consideraram ruim; e $1 \%$ consideraram péssimo, como pode ser observado no gráfico abaixo.

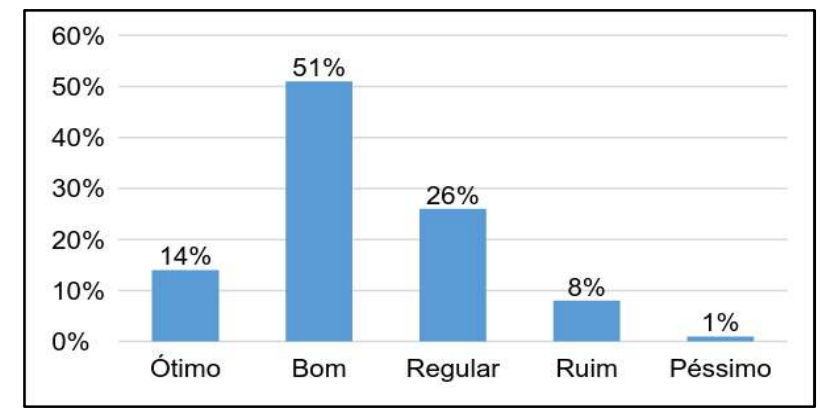

Gráfico 2: Odontologia.

Percebe-se, neste gráfico, que os dados são positivos quanto à oferta desse serviço tendo $65 \%$ de aprovação, somando-se ótimo e bom. Em entrevista, a enfermeira afirmou que o (a) dentista possui todos os equipamentos necessários e que os profissionais da área (um (a) dentista e um técnico em saúde bucal) atuam diariamente sendo distribuídas 20 fichas diárias: 10 para o período da manhã e 10 para o período da tarde. Os dentistas fazem acompanhamento dos pacientes e os encaminham para outros pontos de atendimentos que realizam procedimentos de complexidade maior quando necessário.

No entanto, apesar de uma avaliação predominantemente positiva, houve uma porcentagem negativa significativa para esse serviço somando-se $9 \%$ os que consideraram ruim e péssimo. E para essas pessoas os motivos foram os seguintes: 'horário de atendimento do dentista'; 'diagnóstico incorreto'; 'falta de material para alguns procedimentos'. É notório que as reclamações são poucas, porém são significativas para a análise dos dados. Foi observado pela pesquisadora que ocorre o mesmo com o (a) dentista em relação ao horário de atendimento, visto que ele (a) chega a partir das $9 \mathrm{~h}$ da manhã fazendo com que se acumule o número de pacientes para atendimento, causando reclamações, pois o paciente deve chegar às $7 \mathrm{~h}$ da manhã para aguardar um atendimento que ocorrerá depois após às $9 \mathrm{~h}$.

De acordo com a Política Nacional de Atenção Básica (PNAB) do Ministério da Saúde, o dentista deve realizar os procedimentos clínicos da Atenção Básica em saúde bucal, incluindo atendimento das urgências e pequenas cirurgias ambulatoriais, realizar a atenção integral em saúde bucal (promoção e proteção da saúde, prevenção de agravos, diagnóstico, tratamento, reabilitação e manutenção da saúde) individual e coletiva a todas as famílias, encaminhar e orientar usuários, quando necessário, a outros níveis de assistência, mantendo sua responsabilização pelo acompanhamento do usuário e o segmento do tratamento.

Thoenig (2000) afirma que as avaliações podem ser um problema para os executores da política, pois os resultados podem não ser os esperados e causar constrangimento público. Neste caso, houve uma boa 
avaliação, porém, os pontos negativos levantados podem não ser o esperado pelos executores. Nesse ponto, pode-se acrescentar um tipo de avaliação definido por Secchi (2013), a avaliação in itinere, conhecida também como avaliação formativa ou monitoramento. Ou seja, uma forma de monitoramento desses profissionais quanto aos horários de chegada e saída da UBS.

Diante do que foi exposto, conclui-se que o serviço atende parte do que é descrito pelo PNAB, implicando positivamente na avaliação dos usuários, como é mostrado nos dados acima, visto que as ações realizadas pelos profissionais responsáveis pela odontologia se encaixam conforme os documentos apresentados pelo SUS, porém, falta monitoramento por parte dos gestores quanto aos horários dos profissionais para que não se acumule pessoas sem atendimento e para que não diminua a quantidade de pacientes atendidos no dia.

\section{Enfermagem}

A terceira questão a respeito dos serviços foi em relação à enfermagem. Questionou-se aos respondentes sobre o atendimento realizado pelo (a) enfermeiro (a) e os técnicos em enfermagem na Unidade frequentada por ele (a) em seu bairro. Do total, 15\% consideraram este serviço ótimo; $64 \%$ consideraram bom; $12 \%$ consideraram regular; $6 \%$ consideraram ruim; e 3\% consideraram péssimo, como pode ser observado no gráfico abaixo.

O gráfico a seguir mostra os níveis de satisfação para o serviço de enfermagem nas Unidades Básicas. Nota-se que teve uma boa avaliação por parte dos entrevistados, pois se soma $79 \%$ de aprovação entre ótimos e bons. Alguns entrevistados afirmaram que 'os enfermeiros trabalham mais que o médico'; 'na medida do possível fazem o seu trabalho'; 'são simpáticos'; 'atendem bem'; 'fazem os procedimentos com delicadeza e paciência'; 'estão sempre prontos a atender'.

De acordo com a entrevista com a enfermeira foram levantados dados quanto ao papel da enfermagem na Unidade. A mesma informou desenvolver atividades como planejamento (tanto para a Unidade quanto para os Agentes Comunitários de Saúde - ACS), exame preventivo, pré-natal, PSE (Programa Saúde na Escola), visitas domiciliares, acompanhamento de pacientes, conta com o auxílio de técnicos de enfermagem que realizam troca de curativos, imunizações, verificação de pressão, pesagem e também atua como responsável administrativo da Unidade, visto que não existe um administrador específico para a função.

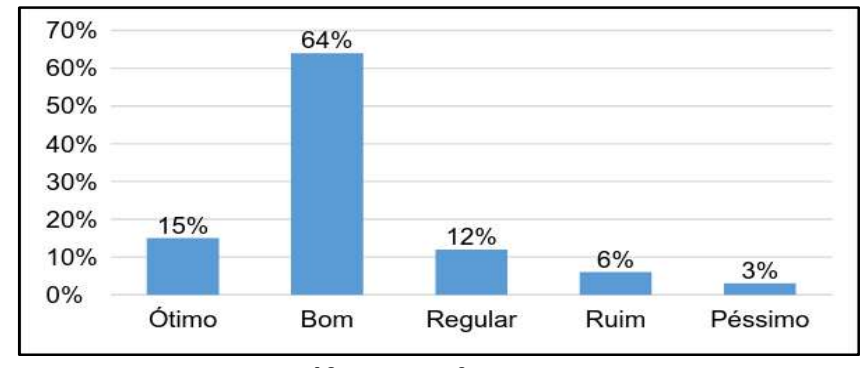

Gráfico 3: Enfermagem. 
Destaca-se que, para esse serviço, houve uma porcentagem pequena de ponto negativo somando $9 \%$ que avalia ruim e péssimo. Nesse ponto, os entrevistados questionaram a respeito do conforto que não possuem em relação a sala de enfermagem, visto que nesse lugar são executados diversos serviços como exame preventivo e pré-natal, além de planejamento realizado pelos profissionais desse setor.

Entretanto, cabe destacar que os pacientes têm um contato maior com os profissionais responsáveis pela enfermagem ocasionando para que os resultados tenham sido mais positivos do que negativo. Vale também citar que a entrevista foi realizada com profissionais desse setor possibilitando um viés para uma avaliação positiva para o ambiente de trabalho do próprio entrevistado.

De acordo com Thoenig (2000), alguns fatores, como a existência de crenças e interesses na organização; ocorrência de conflitos de interesses; mudanças no pessoal encarregado; inflexibilidade das regras e dos padrões operacionais; cortes orçamentários e alterações no ambiente político podem interferir no resultado da avaliação, como é o caso desse setor em referência.

De acordo com os documentos do SUS, é papel do enfermeiro realizar assistência integral às pessoas e famílias na UBS e, quando indicado ou necessário, no domićlio e/ou nos demais espaços comunitários; realizar consultas de enfermagem, solicitar exames complementares e prescrever medicações, observadas as disposições legais da profissão e conforme os protocolos ou outras normativas técnicas estabelecidas pelo Ministério da Saúde, os gestores estaduais, os municipais ou os do Distrito Federal; planejar, gerenciar, coordenar e avaliar as ações desenvolvidas pelos ACS (Agentes Comunitários de Saúde); supervisionar, coordenar e realizar atividades de educação permanente dos ACS e da equipe de enfermagem; contribuir e participar das atividades de Educação Permanente do Auxiliar de Enfermagem; e participar do gerenciamento dos insumos necessários para o adequado funcionamento da UBS.

Portanto, conclui-se que, o desempenho da enfermagem nas Unidades está em consonância com o que é descrito nos documentos oficiais do Ministério da Saúde apesar da estrutura para o desenvolvimento desses profissionais seja carente de melhorias. Percebe-se que boa parte da população está satisfeita com o serviço como é mostrado no gráfico e como foi discutido anteriormente.

\section{Infraestrutura}

Quanto a esse ponto divide-se em alguns subpontos que foram considerados fundamentais que houvesse em todas as Unidades, independentes do tamanho e da quantidade de pacientes atendidos em sua microrregião. São eles: sala para vacina (imunizações), sala para nebulização e acessibilidade para deficientes físicos. No tocante à aplicação de vacinas foi questionado aos pacientes se há uma sala específica para aplicação de vacinas e sobre a frequência com a qual essas imunizações acontecem. Constatou-se que em todas as Unidades existem esse tipo de sala onde fica um técnico em enfermagem que realiza imunizações diariamente. Quanto à satisfação dos pacientes em relação a esse tipo de serviço houve uma boa aprovação, como será possível observar na tabela 4, no qual 84\% dos entrevistados consideram o serviço ótimo e bom. O manual de estrutura da UBS determina como deve ser esse tipo de sala da seguinte maneira: "Por se tratar de ambiente que será utilizado em boa parte por usuários sadios, na determinação dos fluxos de pacientes preveja a localização desta sala, de forma que o usuário não transite nas demais dependências da 
UBS" (BRASIL, 2016). Porém, a sala de aplicação de vacinas em todas as Unidades, como foi observado pela pesquisadora, fica localizada na parte final das Unidades desconsiderando totalmente o que é descrito pelo documento do SUS.

Tabela 4: Aplicação de vacinas.

\begin{tabular}{|c|c|}
\hline Ótimo & $7 \%$ \\
\hline Bom & $77 \%$ \\
\hline Regular & $9 \%$ \\
\hline Ruim & $3 \%$ \\
\hline Péssimo & $4 \%$ \\
\hline
\end{tabular}

Para isso, é necessário que se entenda a lógica do SUS, como ele deve ser planejado e funcionar para cumprir um compromisso que é assegurar a todos, indiscriminadamente, serviços e ações de saúde de forma equilibrada, adequada e progressiva (CARVALHO, 2013). Para tanto, ainda do que foi observado pela pesquisadora e em concordância com os entrevistados pode-se constatar que as salas de vacina das Unidades são pequenas, a infraestrutura não é confortável pois não possui todos os equipamentos necessários para a comodidade do profissional responsável e dos pacientes.

Com isso, nota-se um desacordo com o que os critérios do SUS, com a qual a PNAB determina que “[...] as salas devem possuir bancadas com pia, torneiras com fechamento que dispense o uso das mãos, 1 mesa tipo escritório com gavetas, 3 cadeiras, armários sobre e sob bancada, porta-papel-toalha, portadispensador de sabão líquido, lixeira com tampa e pedal, 1 refrigerador de 260L e computador" (BRASIL, 2016). Isso explica o fato de $16 \%$ dos pacientes considerarem o serviço regular, ruim e/ou péssimo.

Em relação à sala para nebulização (inalação), de acordo com as enfermeiras entrevistadas somente uma das quatro unidades pesquisadas possuía uma sala apropriada para o atendimento, especificamente uma das Unidades recém-construídas na cidade. Em relação à satisfação do usuário, observado na tabela 5, apenas $18 \%$ consideram ótimo e bom esse serviço; $23 \%$ consideram ruim e péssimo; $37 \%$ consideram que não possui uma sala apropriada para a oferta do serviço; e $13 \%$ dos entrevistados consideram que desconhecem se existe ou não uma sala específica para nebulizações.

Tabela 5: Sala para nebulização.

\begin{tabular}{|c|c|}
\hline Ótimo & $2 \%$ \\
\hline Bom & $16 \%$ \\
\hline Regular & $9 \%$ \\
\hline Ruim & $11 \%$ \\
\hline Péssimo & $12 \%$ \\
\hline Não possui & $37 \%$ \\
\hline Desconhece & $13 \%$ \\
\hline
\end{tabular}

De acordo com o exposto, nota-se que os resultados não foram satisfatórios a respeito desse serviço, visto que em entrevista com a enfermeira de três Unidades e como foi observado pela pesquisadora podese confirmar que de fato não existe uma sala específica para esse tipo de atendimento. Essa fase da avaliação envolve necessariamente um julgamento, uma atribuição de valor, uma medida de satisfação ou insatisfação, tal como aprovação ou desaprovação a uma política pública (SAMOTO, 2013).

Em algumas Unidades os pacientes ficam totalmente em estado de desconforto dispostos em um corredor que dar acesso a outras salas pelo fato de possuir apenas o equipamento para o atendimento desconsiderando o que é descrito pelo SUS: 'a sala para nebulização deve ser uma sala que comporte cadeiras 
ou bancos que servirão para a acomodação confortável dos pacientes durante o procedimento'. Portanto, o resultado negativo confirma tudo que foi observado, descrito nas entrevistas e avaliado pelos pacientes. Porém, esse resultado contesta com o que foi observado no Manual de Estrutura da UBS onde consta que esse tipo de sala é item obrigatório em todas as Unidades.

Também foi questionou-se os pacientes a respeito da acessibilidade das Unidades para pessoas portadoras de deficiências e com dificuldade de locomoção. Os resultados não foram positivos: segundo os respondentes, conforme retratado na tabela 6 , apenas $9 \%$ consideraram o serviço ótimo e bom; $28 \%$ consideram regular e $41 \%$ consideram ruim e péssimo, ou seja, $41 \%$ estabeleceram um ponto negativo para o serviço de acessibilidade na UBS. $27 \%$ dos entrevistados consideram que não possui esse serviço e $5 \%$ desconhecem.

Tabela 6: Acessibilidade.

\begin{tabular}{|l|c|}
\hline Ótimo & $1 \%$ \\
\hline Bom & $8 \%$ \\
\hline Regular & $28 \%$ \\
\hline Ruim & $22 \%$ \\
\hline Péssimo & $19 \%$ \\
\hline Não possui & $27 \%$ \\
\hline Desconheço & $5 \%$ \\
\hline
\end{tabular}

A fala das enfermeiras de duas Unidades confirma o que os dados acima mostram: apenas duas das Unidades entrevistadas possuem somente uma rampa acessível para cadeirantes; as outras duas não possuem nenhum tipo de acessibilidade, não obedecendo a descrição do Manual de Estrutura da UBS, no qual se determina que todas as Unidades devem obrigatoriamente possuir espaços adaptados para portadores de deficiência. Todo o projeto da estrutura física da UBS deve considerar adequações que permitam o acesso de pessoas deficientes e de pessoas com limitações, como rampas de acesso, portas com dimensões ampliadas, maçanetas do tipo alavanca, barras de apoio, etc. (BRASIL, 2016). De maneira geral, quanto à infraestrutura como um todo das Unidades entrevistadas, obteve-se os seguintes níveis de satisfação.

Tabela 7: Infraestrutura.

\begin{tabular}{|l|l|}
\hline Ótimo & $5 \%$ \\
\hline Bom & $13 \%$ \\
\hline Regular & $30 \%$ \\
\hline Ruim & $36 \%$ \\
\hline Péssimo & $16 \%$ \\
\hline
\end{tabular}

Nota-se que a infraestrutura das Unidades não fora bem avaliadas por seus usuários, pois, apenas $18 \%$ consideram ótimo e bom, e $66 \%$ consideram ruim e péssimo. Conclui-se um ponto muito negativo em relação à infraestrutura das Unidades Básicas discordando com o que é descrito no manual de estrutura da UBS que diz que 'o espaço físico da Unidade Básica de Saúde, deve proporcionar uma atenção acolhedora e humana tanto para os trabalhadores e profissionais de saúde quanto para os usuários'. Os espaços devem ser planejados de forma a proporcionar um ambiente confortável, incluindo adequações de luminosidade, 
temperatura, ruídos, posicionamento dos assentos para proporcionar interação entre os indivíduos, entre outros.

De acordo com o que fora observado pela pesquisadora as Unidades apresentam precariedade em toda a sua estrutura, pois as UBS não possuem todas as salas apropriadas para os atendimentos como é descrito no manual de estrutura; a estrutura física (paredes, banheiros, piso) apresentam falhas, tal como as paredes com mofo e precisando de reforma, o piso com falhas que prejudicam a locomoção de quem possui limitações e/ou utilizam equipamentos especiais, os banheiros sujos sem nenhuma adaptação e conforto para os usuários. Em consonância, pode-se observar que algumas Unidades foram adaptações realizadas em casas de moradias adquiridas pela prefeitura do munícipio não obedecendo nenhum critério estabelecido pelo SUS levando os usuários a uma situação desagradável. O manual de estrutura da UBS determina que:

Os materiais de revestimentos das paredes, tetos e pisos devem ser todos laváveis e de superfície lisa. Todo o projeto da estrutura física da UBS deve considerar adequações que permitam o acesso de pessoas deficientes e de pessoas com limitações, como rampas de acesso, portas com dimensões ampliadas, maçanetas do tipo alavanca, barras de apoio etc. Os banheiros devem possuir instalação de vaso sanitário, lavatórios, torneiras com fechamento que dispense o uso das mãos, espelho, porta-papel higiênico, porta-papel toalha, porta dispensador de sabão líquido, lixeira com tampa e pedal. (BRASIL, 2016)

Para tanto, conclui-se que toda avaliação deve ser vista como mecanismo de melhoria no processo de tomada de decisão para a política, a fim de garantir melhores informações e melhor desenvolvimento da política pública. Secchi (2013) orienta que saber se alcançou ou não resultados positivos para determinada política pública não ajuda necessariamente para a orientação da melhoria da política. No entanto, a avaliação de políticas deve ter como finalidade a melhoria das ações visando a qualidade da oferta para os atores envolvidos. Ainda no que diz respeito aos serviços ofertados nas Unidades Básicas de Saúde (UBS), de acordo com o PNAB, tem-se a presença do profissional caracterizado como Agente Comunitário de Saúde (ACS). Seu papel é realizar 'planejamento, busca ativa, captação, cadastramento e acompanhamento das famílias de sua área adstrita'.

Esses profissionais devem dotar-se de recursos materiais, equipamentos e insumos suficientes para o conjunto de ações propostas; estar em contato permanente com as famílias desenvolvendo ações educativas, visando à promoção da saúde e a prevenção das doenças, de acordo com o planejamento da equipe; orientar famílias quanto à utilização dos serviços de saúde disponíveis; desenvolver atividades de promoção da saúde, de prevenção das doenças e de agravos, e de vigilância à saúde, por meio de visitas domiciliares e de ações educativas individuais e coletivas nos domicílios e na comunidade, mantendo a equipe informada, principalmente a respeito daquelas em situação de risco; acompanhar, por meio de visita domiciliar, todas as famílias e indivíduos sob sua responsabilidade, de acordo com as necessidades definidas pela equipe.

Em entrevista com as enfermeiras de todas as Unidades entrevistadas foi questionado se elas realizaram tais atividades e se possuem os materiais necessários para a realização das ações. Todas asseguraram que os ACS realizam visitas domiciliares diariamente, possuem os equipamentos necessários, realizam PSE (Programa Saúde na Escola) juntamente com os demais profissionais envolvidos e realizam, frequentemente, ações de orientação e prevenção de doenças envolvendo toda a população. Diante do que 
foi conversado nas entrevistas perguntou-se aos pacientes, através dos questionários, sobre a frequência de ações de orientação e prevenção realizadas pelos ACS. Os resultados são apresentados na tabela 8.

Tabela 8: Agente Comunitário de Saúde.

\begin{tabular}{|l|l|}
\hline Realiza mensalmente & $6 \%$ \\
\hline Realiza semanalmente & $0 \%$ \\
\hline Realiza frequentemente & $10 \%$ \\
\hline Realiza Poucas Vezes & $80 \%$ \\
\hline Nunca realiza & $4 \%$ \\
\hline
\end{tabular}

Percebe-se que os resultados não condizem com o que foi apresentado pelas enfermeiras, visto que, todas asseguraram que as ações eram realizadas frequentemente e a tabela nos mostra que a população considera que os ACS realizam com pouca frequência as ações de orientação e prevenção de doenças. Não houve total consonância com o Manual das UBS, pois os ACS realizam sim orientações às famílias, porém, com pouca frequência e isso não foi suficiente para uma avaliação positiva por parte dos pacientes.

\section{Satisfação geral}

Por fim, foi questionado a respeito da satisfação de cada paciente com a Unidade Básica frequentada por ele em seu bairro. Obteve-se um resultado regular pois apenas $1 \%$ dos respondentes se considera muito satisfeito, $13 \%$ satisfeito, somando-se $14 \%$ os que de alguma forma sentem-se satisfeitos com os serviços oferecidos pela UBS do seu bairro. Porém, $68 \%$ estão razoavelmente satisfeitos e pouco satisfeitos, e $18 \%$ estão insatisfeitos com os serviços oferecidos.

Tabela 9: Satisfação do paciente.

\begin{tabular}{|c|c|}
\hline Muito satisfeito & $1 \%$ \\
\hline Satisfeito & $13 \%$ \\
\hline Razoavelmente satisfeito & $35 \%$ \\
\hline Pouco satisfeito & $33 \%$ \\
\hline Insatisfeito & $18 \%$ \\
\hline
\end{tabular}

Diante desses dados expostos, observa-se uma necessidade de mudança no planejamento das UBS para que, em conformidade com a política do SUS, seja de fato oferecido aos pacientes um atendimento de qualidade, onde os mesmos possam ser atendidos de maneira a sanar as suas necessidades. Pois, se a Unidade possui recursos para isso os níveis de avaliação deveriam ser melhores. No entanto, destaca-se a precariedade na estrutura vivenciada por cada uma, porém isso não justifica que haja um mal planejamento por parte dos gestores, visto que foi constatado que todas as Unidades possuem os profissionais necessários para o atendimento.

Conclui-se que para que os níveis de satisfação aumentem devem haver mudanças grandes em todos os pontos negativos apresentados. Como afirmam Engel et al. (2009), Tahan-Santos (2011), Carvalho (2013), Samoto (2013) e Carvalho et al. (2014), a atenção básica, considerada atenção primária, é o primeiro contato do paciente com o Sistema Único de Saúde (SUS), e, portanto, o componente mais importante do Sistema. 


\section{CONSIDERAÇÕES FINAIS}

A presente objetivou analisar os serviços prestados nas unidades básicas de saúde (UBS) segundo os critérios do Sistema Único de Saúde (SUS), além de traçar o perfil das UBS, descrever os critérios do SUS e avaliar os serviços prestados segundo os critérios do SUS em um pequeno município localizado no interior do Rio Grande do Norte. Através da aplicação de questionários com pacientes/usuário das UBS e de entrevistas realizadas com os gestores responsáveis por cada UBS, que no caso da presente pesquisa foi realizado com enfermeiros (as), foi possível traçar o perfil das UBS além de avaliar os serviços prestados por cada uma. Através dos documentos disponibilizados pelo SUS foi possível descrever os critérios adotados para cada serviço que as UBS oferecem ou deveriam oferecer.

Com os documentos que o SUS disponibiliza, foi possível descrever os critérios que as Unidades devem oferecer e com isso fazer uma comparação entre os serviços oferecidos, a avaliação dos pacientes e o que de fato deveria ser oferecido pelas Unidades. De acordo com o que foi respondido pelos pacientes pode-se fazer uma avaliação a respeito dos serviços oferecidos pelas Unidades com a qual os pacientes têm acesso. Tal como, pode-se conhecer os serviços que deveriam ser oferecidos, mas, por carência de recursos e falta de atenção dos gestores, não são oferecidos.

No tocante a análise dos resultados pode-se observar que, após análise do que foi observado pela pesquisadora e respondido pelos pacientes, a uma carência no desenvolvimento das ações de prevenção e orientação por parte dos Agentes Comunitário de Saúde pois eles possuem uma parcela muito importante na parte de orientação para a comunidade em relação a prevenção das epidemias e também por acompanhar a situação de cada família. E foi observado um ponto negativo pela comunidade relacionado a esses profissionais, uma vez que eles deveriam ser melhores avaliados por terem contato maior e direto com a população.

Em relação à infraestrutura das Unidades foi observado uma precariedade em algumas Unidades, visto que muitas delas são adaptações de casas populares sem conforto alguma para os usuários e sem nenhum tipo de acessibilidade. É importante ressaltar que deveriam ser construções que atendessem os critérios estabelecidos pelo SUS, no entanto, na prática o que ocorre é apenas uma forma de remediar essa situação com esse tipo de decisão que é a compra de casa e a adaptação das mesmas ao invés da construção de Unidades em conformidade com a política do SUS.

Para tanto, o estudo apresentou algumas limitações durante a fase de coleta de dados pelo fato de ocorrerem algumas dificuldades como a falta de tempo, falta de recursos, dificuldade em conversar com todos os profissionais que compõem as UBS do município, dificuldade em se visitar todas as UBS do munícipio para uma análise mais precisa da situação de cada uma, dificuldade em se entrevistar um número maior de pacientes das Unidades, dentre outros.

\section{REFERÊNCIAS}

BARROS, A.. Fundamentos de Metodologia Científica. 3 ed. São Paulo: Pearson, 2008.
BRASIL. Ministério da Saúde. Política Nacional de Atenção Básica. Brasília: MS, 2012. 
CARVALHO, B. G.; PEDUZZI, M.; NUNES, E. F. P. A.; LEITE, F. S.; SILVA, J. A. M.. Gerência de unidade básica de saúde em municípios de diferentes portes: perfil e instrumentos gerenciais utilizados. Revista da Escola de Enfermagem da USP, v.48, n.5, p.7-14, 2014.

CARVALHO, G.. A saúde pública no Brasil. Estudos Avançados, São Paulo, v.27, n.78, p.7-26, 2013.

ENGEL, C. L.; NICOLICH, M.; ROCHA, M.. Preventiva: Sistema Único de Saúde. Rio de Janeiro: MedYn, 2009.

GARCIA, R. C.. Subsídios para organizar avaliações da ação governamental. Planejamento e Políticas Públicas, Brasília, n.23, p.7-70, 2001.

GIL, A. C.. Como elaborar projetos de pesquisa. 4 ed. São Paulo: Atlas, 2009.

hochman, G.; ARRETCHE, M.; MARQUES, E.. Políticas públicas no Brasil. 4 ed. Rio de Janeiro: FIOCRUZ, 2014.

LOTTA, G. S.. Implementação de Políticas Públicas: o impacto dos fatores relacionais e organizacionais sobre a atuação dos Burocratas de nível de rua no programa saúde da família. Tese (Doutorado em Ciência Política) Universidade de São Paulo, São Paulo, 2010.
MARCONI, M. A.; LAKATOS, E. V.. Metodologia científica. São Paulo: Atlas, 2004.

RUA, M. G.. Políticas públicas. Florianópolis: UFSC, 2012.

SAMOTO, A. K.. Avaliação da qualidade dos serviços de Atenção Básica, segundo modelo de atenção, na Região de Saúde do Rio Pardo/SP. Dissertação (Mestrado Profissional em Saúde Coletiva) - Secretaria de Estado da Saúde de São Paulo, São Paulo, 2013.

SECCHI, L.. Políticas Públicas: conceitos, esquemas de análise, casos práticos. 2 ed. São Paulo: Cengage Learning, 2013.

SOUZA, C.. Estado do campo da pesquisa em políticas públicas no Brasil. Revista Brasileira de Ciências Sociais, São Paulo, v.18, n.51, p.15-20, 2003.

TAHAN-SANTOS, E.. Estratégia Saúde da Família: satisfação de usuários. Dissertação (Mestrado em Psicologia) Universidade de São Paulo, Ribeirão Preto, 2011.

THOENIG, J. C.. A avaliação como conhecimento utilizável para reformas de gestão pública. Revista do Serviço Público, Brasília, v.51, n.2, p.54-70, 2000.

VERGARA, S. C.. Projetos e relatórios de pesquisa em administração. 9 ed. São Paulo: Atlas, 2007. 